Bull. Chem. Soc. Ethiop. 2017, 31(3), 373-382.

ISSN 1011-3924

(c) 2017 Chemical Society of Ethiopia and The Authors

Printed in Ethiopia

DOI: http://dx.doi.org/10.4314/bcse.v31i3.2

\title{
CLOUD-POINT EXTRACTION AND SPECTROPHOTOMETRIC DETERMINATION OF CLONAZEPAM IN PHARMACEUTICAL DOSAGE FORMS
}

\author{
Hind Hadi Abdullah* \\ Department of Chemistry, College of Science, University of BaghdadJadriyah, Baghdad, Iraq
}

(Received April 28, 2017; Revised November 7, 2017; Accepted November 13, 2017)

\begin{abstract}
Aneco-friendly, simple and very sensitive method was developed for preconcentration and determination of clonazepam (CLO) in pharmaceutical dosage forms using cloud point extraction (CPE) technique. The method is based on cloud point extraction of product from oxidative coupling between reduced CLO and phloroglucinol (PHG) using Triton X-114 as surfactant. The product was extracted by micelles of the non-ionic surfactant (TritonX-114) and subsequently detected spectrophotometrically at specific $543 \mathrm{~nm}$. Under optimal conditions, the linearity of calibration curve was in the range of $0.3-25 \mu \mathrm{g} / \mathrm{mL}$ of CLO $(\mathrm{r}=0.9994)$. Average recoveries for samples were determined to be between $96-101 \%$. The relative standard deviation (RSD) for $3.0 \mu \mathrm{g} / \mathrm{mL}$ of CLO was $(2.5 \%)$. The limits of detection and quantification were 0.11 and $0.37 \mu \mathrm{g} / \mathrm{mL}$ respectively. The suggested method was applied successfully for determination of CLO in commercial tablets.
\end{abstract}

KEY WORDS: Clonazepam, Cloud point extraction, Triton X-114

\section{INTRODUCTION}

Clonazpam, (chemically named; 5-(o-chlorophenyl)-1,3-dihydro-7-nitro-2H-1,4-benzodiazepin2-one) is a benzodiazepine, which in general prescribed for epilepsy, anxiety and insomnia. Further uses include treatment for alcohol withdrawal, skeletal muscle spasms, tardive dyskinesia, and sedation prior to dental and medical procedures [1-3].

Various methods have been reported for determining CLO in either pharmaceutical forms or biological fluids, including RP-HPLC [4-6], automated solid phase extraction-liquid chromatograghy-tandem quadruple mass spectrometry LC-MS/MS in blood [7], chemiluminescence [8], capillary electrophoresis [9], voltammetry [10], silver nanoparticles/multi walled carbon nanotubes modified electrode [11] and flow injection spectrophotometry techniques [12-14]. Spectrophotometric technique combined with cloud point extraction (CPE) is still provided attractive features in routine analyses of metals and organic compounds in many matrices as an alternative of using an expensive instrumentations mentioned above $[15,16]$.

CPE technique (green method) has become the best extraction techniques in comparison with other extraction methods because of its advantages like simplicity, good recovery, high enrichment factor, low consumption of organic solvents and in addition possibility to extraction a wide range of compounds and metals. Surfactant and micelles are increasingly utilized in analytical methods mainly in extraction and preconcentration procedures. CPE (in comparison with other liquid-liquid extraction) exhibits good environmentally friendly properties. The small volumes of extracted solvents or surfactants instead of toxic organic solvents made the CPE more safely methods, in addition the reducing of consumption of the solvents reduces the costs of method and extraction time $[17,18]$.

To the best of our knowledge, there is no work reported in literatures relating to the estimation of CLO drug in any matrices utilizing CPE-spectrophotometric method as a result, the present work is an attempt to establish a new method for the extraction and preconcentration

*Corresponding author. E-mail: hindhadi13@yahoo.com

This work is licensed under the Creative Commons Attribution 4.0 International License 
of CLO drug based on the oxidative coupling reaction and in drug formulations using CPE followed their determination using spectrophotometry.

\section{EXPERIMENTAL}

The absorption spectra and absorbance measurements of analyte were carried out by using a digital double beam spectrophotometer a type of Shimadzu UV-VIS 260 (Shimadzu, KyotoJapan). The absorbance measurements were carried out using $1 \mathrm{~cm}$ path length of quartz matched cells (Cecil, $50 \mu \mathrm{L}$ internal volume) for cloud point extraction measurements, and for the measurements of absorbance, a matched $(1 \mathrm{~cm})$ silica cells had been used. A thermostatic water bath expert (England) was used of CPE experiments. A Hettich, EBA 21 model centrifuge with $50 \mathrm{~mL}$ calibrated centrifuge tubes were used to achieve and separation process.

\section{Reagents and materials}

Reagents and chemicals used in this work were ordinary of analytical grade, and the distilled water used all the time. CLO (Pharmaceutical grade) and excipients were received from state company for Drug Industries and Medical Appliance, SDI, Samara-Iraq. Pharmaceutical dosage forms that containing the studied drug (CLO), were purchased from local commercial suppliers and subjected to analysis : Rivotril ${ }^{\circledR} 2 \mathrm{mg}$ (Hoffman LaRoche, Switzer-land) and Rivotril ${ }^{\circledR} 2$ mg (Roche Farma, Madrid, Spain). All reagents used in this study were of analytical reagent grade.

Solution of CLO $(500 \mu \mathrm{g} / \mathrm{mL})$. Stock solution of reducing CLO was prepared [19] by dissolving $0.0500 \mathrm{~g}$ of CLO in $50 \mathrm{~mL}$ of ethanol, which then transferred into beaker of $125 \mathrm{~mL}$ and a 20 $\mathrm{mL}$ of distilled water, $20 \mathrm{~mL}$ of $11.7 \mathrm{M}$ of $\mathrm{HCl}$, and $3 \mathrm{~g}$ of reducing agent (zinc powder) were added. The reduction process was completed by allowed the beaker to stand for $15 \mathrm{~min}$ at room temperature $\left(25^{\circ} \mathrm{C}\right)$, then the solution was filtered into $100 \mathrm{~mL}$ volumetric flask, washed the residues with distilled water, and finally diluted to the mark with distilled water. Working solution was prepared by appropriate dilutions in water.

Phloroglucinol solution (0.005 M). PHG (M.wt $126.1 \mathrm{~g} / \mathrm{mol}$, purity $99.0 \%$, BDH) solution was freshly prepared by dissolving $0.0631 \mathrm{~g}$ of PHG in distilled water and diluting to $100 \mathrm{~mL}$ with the same solvent in volumetric flasks and then transferred in a brown bottle.

Sodium periodate solution (0.1 M). $\mathrm{NaIO}_{4}$ (M.wt $213.9 \mathrm{~g} / \mathrm{mol}$, purity 99.9\%, Merck) solution were prepared by dissolving $2.14 \mathrm{~g}$ of $\mathrm{NaIO}_{4}$ and diluting to $100 \mathrm{~mL}$ with distilled water in volumetric flask.

Triton $X-114(10 \% v / v)$. This solution was prepared by dissolving $10 \mathrm{~mL}$ of Triton $\mathrm{X}-114$ (purity $>99.9 \%$, Fluka) in distilled water and diluted to mark in $100 \mathrm{~mL}$ volumetric flask with the same solvent.

\section{General CPE procedure for $C L O$}

In a $10 \mathrm{~mL}$ volumetric flask, an amount of CLO standard or sample solution matched within calibration range, $1.5 \mathrm{~mL}$ of PHG solution $(0.005 \mathrm{M}), 0.1 \mathrm{~mL}$ of oxidant $(0.1 \mathrm{M})$, and $1 \mathrm{~mL}$ of Triton X-114 (10\% v/v) were added, mixed and dilute with to mark with water. The content of the flask was transferred into a $10 \mathrm{~mL}$ centrifuging tube and then kept for $20 \mathrm{~min}$ in the thermostatic bath at $65{ }^{\circ} \mathrm{C}$. The separation of two phases was conducted by centrifugation ( 3500 rpm for $5 \mathrm{~min}$ ) and there after cooled down in an ice bath (in order to increase the viscosity of 
the surfactant-rich phase). The aqueous phase was easily poured by inverting the tube. The surfactant-rich phase that contains the complex was dissolved with $0.5 \mathrm{~mL}$ of ethanol and the absorbance of the complex measured at $543 \mathrm{~nm}$ against a reagent blank prepared under similar conditions.

\section{Samples preparation of pharmaceutical for CLO detection}

Thirty tablets containing CLO (Rivotril-2 $\mathrm{mg}$ ) were exactly weighted and powdered then an amount of the powder that equivalent to $50 \mathrm{mg}$ of CLO was dissolved in $30 \mathrm{~mL}$ of ethanol. The solution was filtered and the residue was washed with ethanol and finally the volume was diluted into a $50 \mathrm{~mL}$ volumetric flask to the marked with the same solvent to obtain $1000 \mu \mathrm{g} / \mathrm{mL}$ of CLO. This solution later was transferred into $125 \mathrm{~mL}$ beaker and was reduced as previously described.

\section{RESULTS AND DISCUSSION}

\section{Absorption spectra}

Spectrophotometric investigations were carried out to study the formation of coupling product between CLO and PHG in the presence of the $\mathrm{NaIO}_{4}$ [20]. This reaction was adopted to determine CLO using CPE procedure. The absorption spectra of the colored product and the blank were recorded before and after extraction between 200 and $750 \mathrm{~nm}$ (Figure 1). It was observe that there is a significant absorption bands with shoulder occurred at $543 \mathrm{~nm}$, indicating the formation of a complex between CLO drug and PHG reagent. Whilst pure CLO solution gave absorption maximum at $273 \mathrm{~nm}$, therefore, the wavelength maximum of $543 \mathrm{~nm}$ for color complex was chosen throughout this study.

The mechanism of reaction summarized by reduction the nitro group of CLO compound in first step (using zinc powder with concentrated $\mathrm{HCl}$ ) followed by oxidative coupling between reduced drug and PHG in the presence of sodium periodate as oxidizing agent [20] as show in Scheme 1 .

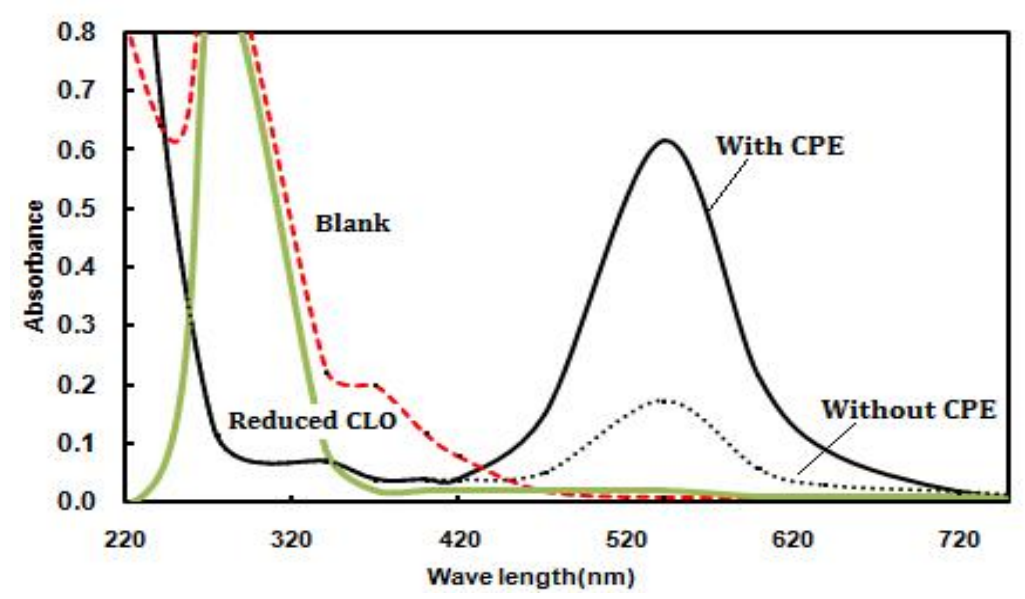

Figure 1. Absorption spectra of $20 \mu \mathrm{g} / \mathrm{mL}$ of reduced CLO treated as described under procedure (pink product) measured against reagent blank with and without CPE, and the reagent blank and reduced CLO measured against distilled water. 
<smiles>O=C1CN(Cc2ccccc2Cl)c2ccc([N+](=O)[O-])cc2N1</smiles>

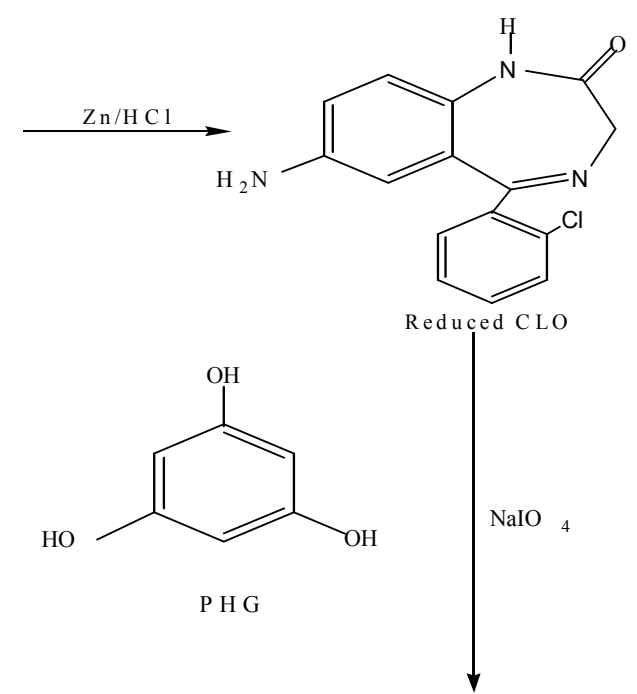<smiles>O=C1CN=C(c2ccccc2Cl)c2cc(Nc3c(O)cc(O)cc3O)ccc2N1</smiles>

Scheme 1. The mechanism of the reaction between CLO and PHG.

\section{Optimization of CPE method}

The effects of the important parameters that affecting the efficiency of the cloud point extraction were studied by using a series of experiments. All the variables that may affecting the sensitivity and stability of the colored product were optimized by variable one parameter with the time, and keeping others fixed. A solution of $100 \mu \mathrm{g}$ of reduced CLO in a $10 \mathrm{~mL}$ final volume (i.e.10 $\mu \mathrm{g} / \mathrm{mL}$ ) was used for the optimization all conditions, with measuring absorbance at $543 \mathrm{~nm}$ against the blank.

\section{Effect of reaction medium}

The reaction carried out without addition any acidic or basic solution and the reaction medium is acidic (produced from reduction process) and to examine the effect of increase the acidic medium, varying volume of $0.5 \mathrm{M} \mathrm{HCL}$ (from $0.0-2.5 \mathrm{~mL}$ ) was added to the reactants and examined by measuring the absorbance at $543 \mathrm{~nm}$. The results indicated that the slightly acidic of the reaction medium was enough for development of the color. More acidic solution was decreased the absorbance (Figure 2). 


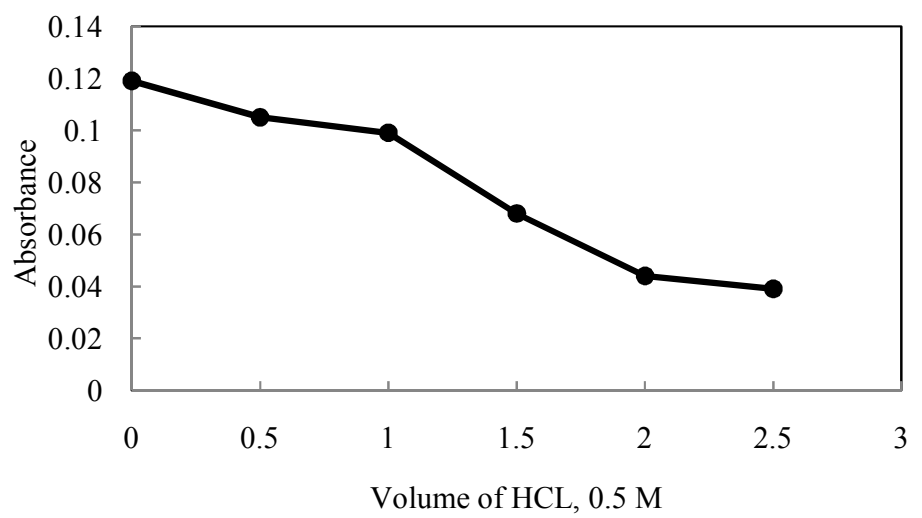

Figure 2. Effect of volume of $0.5 \mathrm{M} \mathrm{HCl}$.

\section{Effect of phloroglcinol concentration}

The effect of PHG concentration on the formation of colored product in Triton X-114 medium was investigated using different volumes in the range $(0.5-4.0 \mathrm{~mL})$ of $0.005 \mathrm{M}$ PHG, the results are presented in Figure 3. It was pointed out the absorbance increased with increasing PHG volume, and reached a maximum at $1.5 \mathrm{~mL}$ then suddenly decreases at high volume. Therefore, a volume $1.5 \mathrm{~mL}$ of $0.005 \mathrm{M}$ PHG was selected as the optimal for complete formation complex.

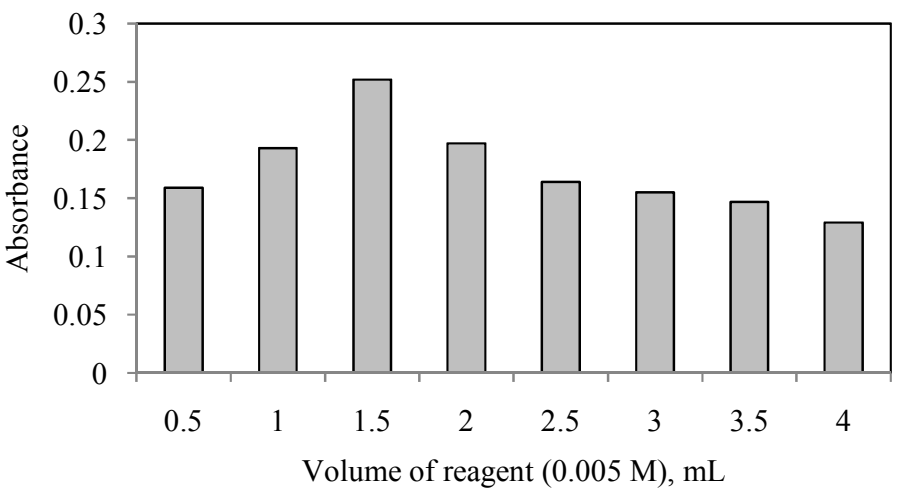

Figure 3. Effect of 0.005 M PHG reagent.

\section{Effect of oxidant concentration}

The results indicated that $\mathrm{NaIO}_{4}$ is a useful oxidizing agent for the proposed reaction, other oxidizing agents have also been tested, but none give product when tried instead of $\mathrm{NaIO}_{4}$. Therefore, the effect of oxidant volume was investigated in the range $(0.05-2.0 \mathrm{~mL})$ of $(0.1 \mathrm{M})$ $\mathrm{NaIO}_{4}$. The results showed that maximum absorbance was maintained if the color is developed using $0.1 \mathrm{~mL} \mathrm{NaIO}_{4}$, and it was used in all the following experiments (Figure 4). 


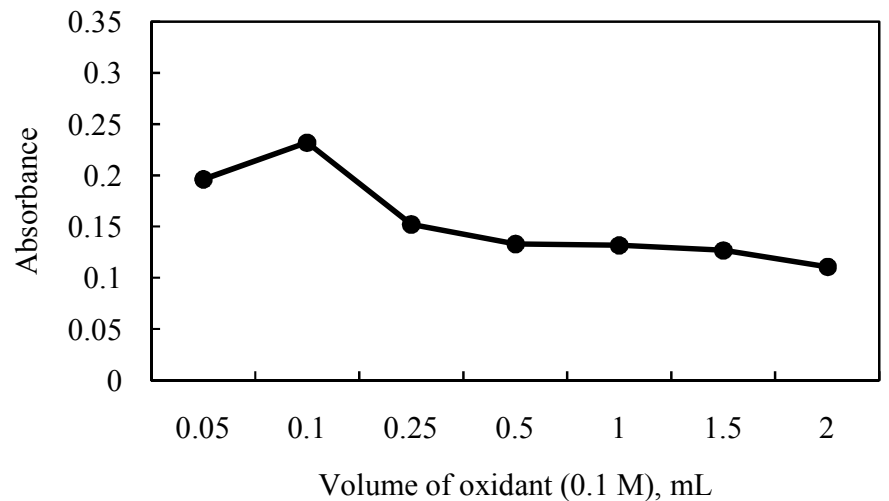

Figure 4. Effect of $0.1 \mathrm{M} \mathrm{NaIO}_{4}$ oxidant.

Effect of surfactant concentration (Triton X-114)

Different kinds of surfactant were studied and it was found that Triton X-114 is the best one used in CPE for the present method. Concentration of the Triton X-114 has an important influence on the extraction efficiency under the cloud point extraction method, due to its important effect to increase extraction efficiency through diminish the phase volume ratio. The effect of the Triton X-114 concentration on the absorbance of the extracted complex was studied within the surfactant volume range of $(0.25-3.5 \mathrm{~mL})$ of $10 \%(\mathrm{v} / \mathrm{v})$ Triton $\mathrm{X}-114$, the concentration and volume used for Triton X-114 very high, so they must be used under heating at a temperature about $50{ }^{\circ} \mathrm{C}$ due to a high viscosity. The results are presented in Figure 5. Indicated that a volume of $1.0 \mathrm{~mL}$ of $10 \%$ Triton $\mathrm{X}-114$ gave the maximum intensity and was used in all the following experiments.

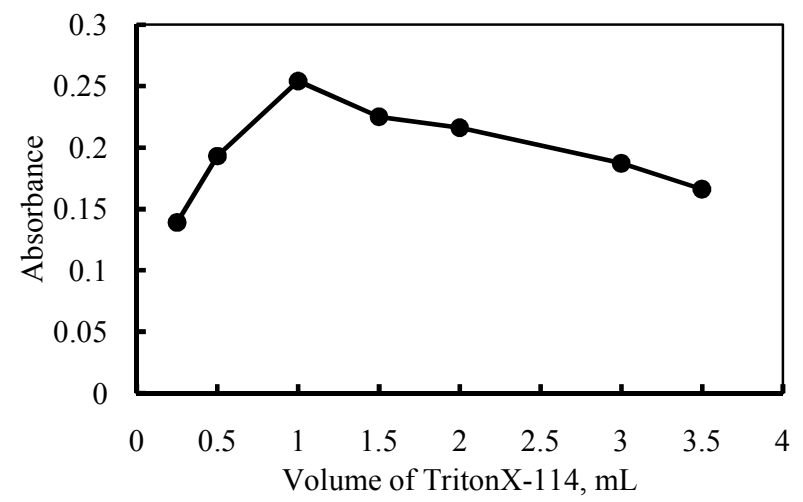

Figure 5. The effect of Triton X-114 concentration. 


\section{Effect of temperature and time of extraction}

In order to achieve an efficient phase separation and easy preconcentration, it is essential to optimize the extraction temperature and incubation time. To study the effect of temperature on the extraction of colored product, a varying of the incubation temperature in the range from 25 to $85^{\circ} \mathrm{C}$ at incubation time for 20 min were applied. It was shown that the maximum absorbance for complex was achieved at $65^{\circ} \mathrm{C}$ (Figure 6). Therefore, an equilibration temperature of $65^{\circ} \mathrm{C}$ was chosen for further experiments.

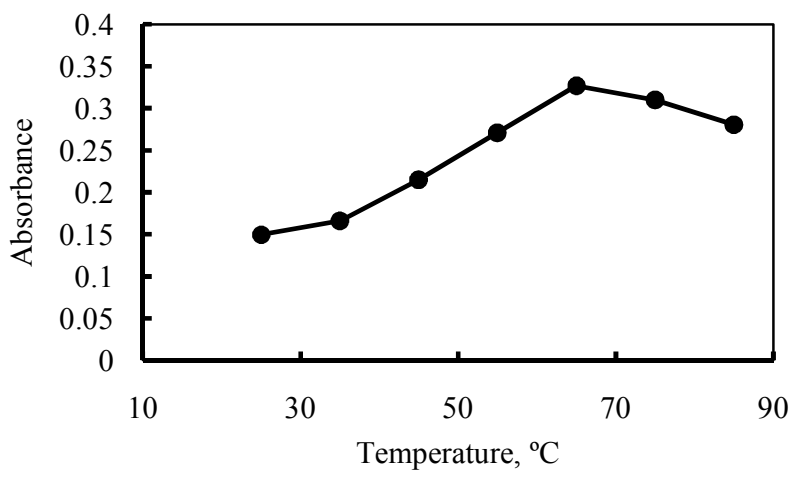

Figure 6. The effect of temperature.

CPE method usually needs a sufficient time to reach to the equilibrium between surfactant-rich and aqueous phases. The dependence of extraction efficiency upon incubation time was studied in the range of 5.0-40 min at $65^{\circ} \mathrm{C}$. An incubation time of $20 \mathrm{~min}$ was sufficient for the separation process. A centrifuge time period of $5.0 \mathrm{~min}$ was selected as optimum, as complete separation occurred within this time and no appreciable improvements were observed for longer periods.

\section{Analytical characteristics}

Under optimum conditions for CLO estimation, the calibration curve was constructed. To the sequence of $10 \mathrm{~mL}$ standard flasks, an increasing amounts of sample containing 3-250 $\mu \mathrm{g}$ of reduced CLO was transferred (cover the range $0.3-25 \mu \mathrm{g} / \mathrm{mL}$ ) then a volume of $1.5 \mathrm{~mL}$ of 0.005 M PHG solution, $0.1 \mathrm{~mL}$ of $0.1 \mathrm{M}$ of solution of $\mathrm{NaIO}_{4}$, and $1 \mathrm{~mL}$ of $10 \%(\mathrm{v} / \mathrm{v})$ Triton X-114 were added and applied the previous extraction procedure. Linear relationships between the absorbance measured and the concentration of the CLO in solution were obtained. The regression equation was derived using the least-squares method [21]. The intercept, slope, correlation coefficient, and molar absorptivity values in addition to values of analytical statistical treatments [22-24, 27] for the calibration curve are calculated and listed in Table 1. Results listed in Table 1 indicate good sensitivity with linearity. A very small values of obtained standard deviation of the residual $\left(\mathrm{S}_{\mathrm{y} / \mathrm{x}}\right)$, intercept $\left(\mathrm{S}_{\mathrm{a}}\right)$, and slope $\left(\mathrm{S}_{\mathrm{b}}\right)$ referred to the precision of the suggested method, and low scattering of points of calibration curve. The results obtain from applied CPE procedure were compared with those without extraction which have been done by the same authors [20].

The preconcentration factor was calculated by dividing the aqueous phase volume by the final volume of the preconcentrated phase, is 20 , whereas the enrichment factor value, 
calculated as the ratio of the slope of the calibration curve of the analyte after preconcentration to the slope of the calibration curve of the analyte before pre-concentration, is 3 .

Table 1. The statistical data of CLO estimation with and without CPE.

\begin{tabular}{|l|l|l|}
\hline \multirow{2}{*}{ Parameter } & \multicolumn{2}{|c|}{ Value } \\
\cline { 2 - 3 } & With CPE & Without CPE [20] \\
\hline Regression equation & $\mathrm{y}=0.0274 \mathrm{x}+0.0573$ & $\mathrm{Y}=0.0088 \mathrm{x}-0.0097$ \\
\hline Correlation coefficient, $\mathrm{r}$ & 0.9994 & 0.9972 \\
\hline Linearity percentage, $\% \mathrm{r}^{2}$ & 99.9 & 99.4 \\
\hline Dynamic range $(\mu \mathrm{g} / \mathrm{mL})$ & $0.3-25$ & $4-45$ \\
\hline Molar absorptivity, $\varepsilon\left(\mathrm{L} / \mathrm{mol}^{2} \mathrm{~cm}\right)$ & 8650.6 & 2778 \\
\hline Sandell sensitivity $\left(\mu \mathrm{g} / \mathrm{cm}^{2}\right)$ & 0.0365 & 0.1136 \\
\hline Slope, $\mathrm{b}(\mathrm{mL} / \mu \mathrm{g})$ & 0.0274 & 0.0088 \\
\hline Intercept, a & 0.0573 & -0.0097 \\
\hline $\mathrm{S}_{\mathrm{y} / \mathrm{x}}$ & 0.0063 & 0.0070 \\
\hline $\mathrm{S}_{\mathrm{b}}$ & 0.0002 & 0.0002 \\
\hline $\mathrm{S}_{\mathrm{a}}$ & 0.0028 & 0.0044 \\
\hline Preconcentration factor & 20 & -- \\
\hline Enrichment factor & 3 & -- \\
\hline Limit of detection, LOD $(\mu \mathrm{g} / \mathrm{mL})$ & 0.11 & 0.70 \\
\hline Limit of detection, LOQ $(\mu \mathrm{g} / \mathrm{mL})$ & 0.37 & 2.33 \\
\hline
\end{tabular}

Accuracy and precision

To evaluate the accuracy and precision of suggested method, two different concentrations of CLO solutions were analyzed according to suggested method in five replicates. The resulting analytical values are summarized in Table 2 . The small values of percentage RSD as precision and percentage relative error as accuracy indicated that the proposed method show a good accuracy and precision.

Table 2. Accuracy and precision of the proposed method.

\begin{tabular}{|c|c|c|c|c|}
\hline \multirow{2}{*}{ Sample } & \multicolumn{3}{|c|}{ CPE } \\
\cline { 2 - 5 } & Added conc. $(\mu \mathrm{g} / \mathrm{mL})$ & Found conc. $(\mu \mathrm{g} / \mathrm{mL})$ & Recovery $(\%)^{*}$ & RSD $(\%)^{*}$ \\
\hline 1 & 5 & 4.82 & 96.3 & 2.13 \\
\hline 2 & 10 & 9.98 & 99.8 & 0.99 \\
\hline
\end{tabular}

*Average of three determinations.

\section{Interference studies}

In order to examine the usefulness of the method, the studied drug (CLO) was determined in the presence of excipients (or additives) [28] which frequently attend to CLO in its dosage forms. The experiment accomplished by measuring the absorbance of solution containing $10 \mu \mathrm{g} / \mathrm{mL}$ of CLO in the presence of fivefold of excipient $(50 \mu \mathrm{g} / \mathrm{mL})$. The good percentage recoveries were obtained indicating no interference was observed from any of these excipients in determining the CLO in its dosage forms.

\section{Determination of CLO in pharmaceutical products}

The developed method was applied to the CLO estimation in two pharmaceutical drugs containing CLO as an active ingredient. The results are given in Table 3. In order to assess the success and competence of a current method, the obtained results were usually compared with resulted maintained from applying the standard method (UV method according BP [3]. The 
obtained results were compared statistically by using two common tests (t-and F-tests at confidence level of 95\%) [25-27]. In all cases, the calculated values were less than the theoretical one, which indicated absence of any considerable difference between each method in accuracy and precision in the estimation of CLO in its medical product.

Table 3. Application of the current and official methods to the determination of CLO in different dosage forms.

\begin{tabular}{|c|c|c|c|c|c|c|}
\hline \multirow[b]{2}{*}{ Dosage form } & \multicolumn{5}{|c|}{ Suggested method } & Official method [3] \\
\hline & $\begin{array}{c}\text { Taken conc. } \\
(\mu \mathrm{g} / \mathrm{mL})\end{array}$ & $\begin{array}{l}\text { Found conc. } \\
(\mu \mathrm{g} / \mathrm{mL})\end{array}$ & $\begin{array}{c}\text { Recovery } \\
(\%)^{*}\end{array}$ & \begin{tabular}{|c|} 
Mean recovery \\
$(\%)$
\end{tabular} & $\begin{array}{l}\text { RSD } \\
(\%)^{*}\end{array}$ & $\begin{array}{c}\text { Mean recovery } \\
(\%)^{*}\end{array}$ \\
\hline \multirow{3}{*}{$\begin{array}{l}\text { Rivotril }(2 \mathrm{mg}) \\
\text { Hoffman-LaRoche- } \\
\text { Switzerland }\end{array}$} & 1 & 0.96 & 96.0 & \multirow[t]{3}{*}{96.7} & 1.89 & \multirow[t]{3}{*}{98.3} \\
\hline & 5 & 4.85 & 97.0 & & 1.94 & \\
\hline & 10 & 9.72 & 97.2 & & 1.02 & \\
\hline \multirow{3}{*}{$\begin{array}{l}\text { Rivotril }(2 \mathrm{mg}) \\
\text { RocheFarma, } \\
\text { S.A-Madrid, Spain }\end{array}$} & 1 & 1.03 & 103.0 & \multirow[t]{3}{*}{101.7} & 1.90 & \multirow[t]{3}{*}{98.5} \\
\hline & 5 & 5.06 & 101.2 & & 1.73 & \\
\hline & 10 & 10.10 & 101.0 & & 1.14 & \\
\hline $\mathrm{t}(2.78)^{\mathrm{c}}$ & 0.32 & & & & & \\
\hline $\mathrm{F}(19.0)^{\mathrm{c}}$ & 4.09 & & & & & \\
\hline
\end{tabular}

"Average of four determination; $\mathrm{c}=$ theoretical value; conc., concentration; RSD = relative standard deviation.

\section{CONCLUSION}

In this work, we introduced an easy and sensitive green method, named cloud point extraction procedure, as safe and inexpensive method for the preconcentration and determination of clonazepam spectrophotometrically. The method validation yielded good results and included linearity, repeatability and sensitivity as compared with other methods. The proposed method can be applied to the determination of clonazepam in tablet.

\section{REFERENCES}

1. Ritter, M.; Albert ferrolewis, L.D.; Mant, T.G. A Textbook of Clinical Pharmacology and Therapeutics, 3rded, Hodder Arnold: UK; 2008; pp 108, 137.

2. Beale, J.M.; Block, J.H. Organic Medicinal and Pharmaceutical Chemistry, 12th ed., Lippincott Williams \& Wilkins, Wolters Kluwer Business: China, Chapter 6, p 501.

3. British Pharmacopoeia on CD.2005, 4, pp 97-118.

4. Mallikarjuna, R.; Agarwal, N.K.; Bichala, P.K.; Som, S. Method development and validation for the simultaneous estimation of desvenlafaxine and clonazepam in bulk \& tablet formulation by RP-HPLC method. Indian J. Res. Pharm. Biotechnol. 2013, 1, 525532.

5. Bhagyasree, T.; Neelam, I.; Ajitha, A.; Uma Maheshwara, R.V. Assay method development and validation for simultaneous estimation of paroxetine and clonazepam by RP-HPLC. Int. J. Pharm. Res. Anal. 2014, 4, 421-427.

6. Rani, N.U.; Sahithi, G.; Divya, K. New RP-HPLC method for simultaneous estimation of desvenlafazine and clonazepam tablets. Int. J. Pharm. Sci. Drug Res. 2015, 7, 182-187.

7. Jing, D.; Shi, Y.; Wang, J. Qualitative and quantitative analysis of clonazepam and its metabolite 7-aminoclonazepam in blood by LC-tandem QTOF/MS and LC-MS/MS. Forensic Sci. 2014, 4, 45-52.

8. Chaichi, M.J.; Alijanpour, S.O. A new chemiluminescence method for determination of clonazepam and diazepam based on 1-ethyl-3-methylimidazolium ethylsulfate/copper as catalyst. Spectrochim. Acta Mol. Biomol. Spectrosc. 2013, 24, 36-41. 
9. Wozniakiewicz, A.; Wietecha-posluszny, R.; Wozniakiewicz, M.; Bryczek, E.; Kosscielniak, P. A quick method for determination of psychoactive agents in serum and hair by using capillary electrophoresis and mass spectrometry. J. Pharm. Biomed. Anal. 2015, $111,177-185$.

10. Honeychurch, K.C.; Brooks, J.; Hart, J.P. Development of a voltammetric assay using screen-printed electrodes for clonazepam and its application to beverage and serum sample. Talanta, 2016, 147, 510-515.

11. Habibi, B.; Jahanbakhshi, M. Silver nanoparticles/multi walled carbon nanocomposite modified electrode: Voltammetric determination of clonazepam. Electrochim. Acta 2014, 118, 10-17.

12. Al-Abachi, M.Q.; Hadi, H. Flow injection-spectrophotometric determination of clonazepam based on its oxidative condensation with promethazine hydrochloride. Al-Mustansiriyah $J$. Sci. 2015, 26, 38-42.

13. Al-Abachi, M. Q.; Hammoudi, M. A. The use of spectrophotometric batch and flow injection estimation of clonazepam drug in pure and pharmaceutical preparations. Iraqi $J$. Sci. 2015, 56, 2115-2125.

14. Al-Abachi, M.Q.; Hammoudi, M.A. Batch and flow injection spectrophotometric methods for the determination of clonazepam in pharmaceutical preparation via oxidative coupling with pyrocatecol. Iraqi J. Sci. 2015, 56, 898-908.

15. Khammas, Z.A.A.; Jawad, S.K.; Ali, I.R. A new approach for extraction and determination of manganese in environmental samples using cloud-pointextraction coupled with spectrophotometry. Chem. Sci. Trans. 2014, 3, 255-267.

16. Khammas, Z.A.A.; Jawad, S.K.; Ali, I.R. A new spectrophotometric determination of chromium (VI) as $\mathrm{Cr}_{2} \mathrm{O}_{7}{ }^{2-}$ after cloud-point extraction using a laboratory made organic reagent. Global J. Sci. Frontier Res. Chem. 2013, 13, 9-19.

17. Ojeda, C.B.; Rojas, F.S. Separation and preconcentration by a cloud point extraction procedure for determination of metals: An overview. Anal. Bioanal. Chem. 2009, 394, 759782.

18. Ojeda, C.B.; Rojas, F.S. Separation and preconcentration by cloud point extraction procedure for determination of ions: resent trend in application. Microchim. Acta 2012, 177, $1-21$.

19. Hadi, H. Spectrophotometric determination of clonazepam in pure and dosage forms using charge transfer reaction. Iraq J. Pharma. Sci. 2015, 24, 25-32.

20. Hadi, H.; Mouayed, M. Determination of clonazepam in pharmaceutical preparations using simple high-throughput flow injection system .J. Anal. Chem. 2017, 72, 226-233.

21. Farrant, T.J. Practical Statistics for the Analytical Scientist, Thomas Graham House, LGC: U.K.; 1997.

22. Kellner, R.; Mermet, J.M.; Otto, M.; Widmer, H.M. Analytical Chemistry, Wiley-VCH: New York; 1998.

23. Hayter, A.J. Probability and Statistics, 2nd ed., Thomson Learning: Canada; 2002.

24. Harry, D. Modern Analytical Chemistry Spectroscopy Method of Analysis, the MC-GramHill Companies: USA; 2000, chapter 10, p 404.

25. Oxtoby, D.W.; Gillis, H.P.; Nachtrieb, N.H. Principles of Modern Chemistry, 4th ed., Saunders College Publishing: New York; 1999.

26. Rouessac, F.; Rouessac, A. Chemical Analysis, $5^{\text {th }}$ ed., John Wiley and Sons, Ltd: New York; 2000.

27. Miller, J.N.; Miller, J.C. Statistics and Chemometrics for Analytical Chemistry, 5th ed., Prentice Hall: England; 2005.

28. Gouda, A.A.; El Sheikh, R.; Amin, A.S.; Ibrahim, S.H. Spectrophotometric methods based on charge transfer complexation of some antifungal drugs in pure and dosage forms. Bull. Chem. Soc. Ethiop. 2016, 30, 333-346. 